\title{
Fast-Bleeped: A to E Series - Breathing: Acute Shortness of Breath
}

\author{
Guilherme Movio, 4th Year Medical Student, ${ }^{1}$ Dr. Anna Haley, Specialty Trainee Year 3 (ST3) in Respiratory \\ Medicine, ${ }^{2}$ Dr. Andrew Clarke, Speciality Trainee Year 6 (ST6) Acute Medicine and Intensive Care ${ }^{3}$ \\ ${ }^{1}$ Lancaster Medical School, Lancaster University, ${ }^{2}$ University Hospitals of Morecambe Bay Foundation Trust, ${ }^{3}$ Royal Free London Foundation Trust
}

\section{CASE SCENARIO OF MR. W}

You are the medical Foundation Year 1 (FY1) doctor on-call at night in a busy district general hospital. You receive a bleep from a nurse on the respiratory ward who is concerned about Mr. W's breathing. You go there immediately to assess the patient.

You are the first doctor to arrive on the ward. Mr. W is a 48-year-old Caucasian male in respiratory distress. The nurses inform you that he was admitted earlier in the day following an exacerbation of his chronic obstructive pulmonary disease (COPD). They explain that he was being supported with noninvasive ventilation (NIV) when he suddenly started to find it more difficult to breathe. The patient has taken off his mask and the nurses have attached oxygen via nasal cannula.

His observations are:

- Heart Rate (HR): 125 beats per minute

- Respiratory Rate (RR): 36 respirations per minute

- Saturations: $85 \%$ on 3 litres/minute of oxygen via nasal cannula

- Blood Pressure (BP): 90/40mmHg

- Temperature: $36.1{ }^{\circ} \mathrm{C}$

On general inspection you notice usage of accessory muscles, tracheal deviation to the right and that the left side of his chest is not moving.

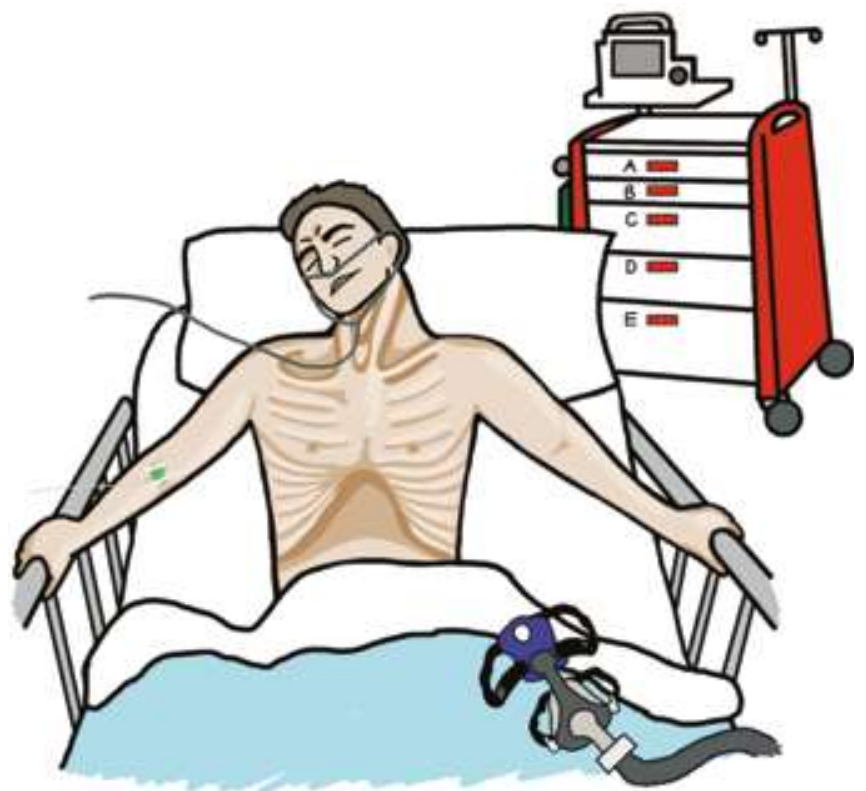

Figure 1: Depicting Mr. W, as you arrived on the ward.

\section{WHAT SHOULD BE YOUR INITIAL APPROACH TO MR. W?}

Respiratory distress is a medical emergency and should be dealt with urgently. You should assess the patient in a systematic way using an A-E approach.'
(A)irway: In this case you find that the patient can tell you he is feeling breathless. The fact that the patient is managing to speak at all, means that his airway is patent.

(B)reathing: We need to assess both processes of oxygenation and ventilation.

The quickest way to assess oxygenation will be by measuring his oxygen saturations with a pulse oximeter. In our case example, the patient's oxygen saturations are low, so providing additional supplemental oxygen will be our first priority in his clinical management.

When a patient is deteriorating acutely on NIV, there are several potential possible problems. There may be a problem with the NIV machine, a new pathology or deterioration with the patient or a problem with the NIV-patient interface, for example there may be an issue with mask fit. In an emergency, it may be appropriate to remove NIV in the first instance to simplify the clinical problem. After doing this, you should administer high-flow oxygen. In practice, this is done by connecting a non-rebreathe mask with an oxygen reservoir to the oxygen tap on the wall or oxygen cannister on the bed trolley and opening the tap to a flowrate of 15 liters per minute. You should ensure that the reservoir is full. ${ }^{2}$

You realise that this patient has a past medical history of COPD causing type 2 respiratory failure. It will be important to carefully titrate his oxygen saturations to achieve target oxygen saturations of $88-92 \%$ but in the emergency situation, the initial priority is to correct hypoxia. Following your complete assessment and if the patient stabilises it will be important to down titrate his oxygen supply so as not to over-achieve his oxygen saturations target. ${ }^{2,3}$

He has tachypnoea and other physical signs which imply an additional ventilatory problem. These include usage of his accessory muscles, deviation of his trachea to the right and reduced chest wall movement on the left. You cannot auscultate breath sounds on the left and the percussion tone is resonant. ${ }^{3}$ You have identified that Mr. W has a significant problem with his breathing (a ' $B$ ' problem) and you ask a member of the nursing team to put out a medical emergency call so that help comes quickly as this patient is at risk of deteriorating even further.

(C)irculation: Mr. W has signs of haemodynamic compromise with significant tachycardia and hypotension. You should attach him to a cardiac monitor and assess his heart rhythm. It will also be a good idea to set the blood pressure cuff to cycle automatically for up-to-date blood pressure information.

(D)isability: Mr. W complains of pain on the left side of his chest. You ask a nurse to check a capillary blood glucose which is within normal range. He is alert but looks panicked.

(E)verything else: There is no abdominal pain or tenderness on palpation. There is no calf tenderness, erythema or swelling that could suggest a lower limb deep vein thrombosis. There are no signs of external bleeding.

The medical emergency team (MET) arrive and without further delay there is consensus that this patient is likely to be 
suffering from an acute tension pneumothorax, which requires urgent life-saving intervention.

\section{WHAT ARE THE DIFFERENTIAL CAUSES OF ACUTE SHORTNESS OF BREATH?}

We can divide the causes of acute breathlessness according to the time of onset, and the presence or absence of additional clinical features, as highlighted in Table 1. But remember, not all features need to be present to make the diagnosis.

\section{WHAT IS THE PATHOPHYSIOLOGY OF A PNEUMOTHORAX, RELATED TO THE CLINICAL SIGNS SEEN?}

A pneumothorax is caused by air within the pleural space. In spontaneous pneumothorax it is often caused by a rupture of a visceral pleural bleb. These are assumed to be congenital malformations of connective tissues. These patients are often tall and thin. ${ }^{6}$

Secondary pneumothorax occurs due to underlying conditions including COPD, asthma, and interstitial lung disease ${ }^{3}$ these conditions make the pleural wall more fragile and prone to damage.

In a tension pneumothorax, a one-way-valve forms within the visceral pleura allowing air to move out from the lung into the pleural space, but not back. This leads to accumulation of gas within the pleural space with every inspiration, and a resultant rise in intra-pleural pressure. Initially, this leads to collapse of the underlying lung. As the intra-pleural pressure continues to rise, this pushes the mediastinum towards the contra-lateral side (picked up clinically by deviation of the trachea away from the affected side) and reduces the flow in the major blood vessels, including the vena cava. This leads to reduced venous return to the right side of the heart and rapid cardiovascular collapse. ${ }^{3}$

A patient with pneumothorax usually presents with pleuritic chest pain and shortness of breath. Alongside pneumothorax, the differential diagnosis for these symptoms include pneumonia with pleurisy, pleural effusion, and pulmonary embolism. ${ }^{3}$ The parietal pleura is innervated by the phrenic and intercostal nerves, which is why pleural stretch from pneumothorax leads to pleuritic pain. ${ }^{7}$ Key findings that increase the likelihood of pneumothorax include tachypnoea and unilaterally reduced chest expansion with a resonant percussion note. ${ }^{3}$ Late clinical findings that will make you concerned that this is a large or tension pneumothorax include deviation of the trachea (reflecting deviation of the mediastinum). Cardiovascular instability (significant tachycardia and/or hypotension) is a sign of tension pneumothorax and should prompt urgent intervention, before waiting for a chest $x$-ray to confirm the diagnosis. ${ }^{3,6}$ Patients receiving positive pressure ventilation are likely to deteriorate more quickly as the intra-pleural pressure will increase faster.

\section{HOW CAN PNEUMOTHORACES BE CLASSIFIED?}

A pneumothorax can be divided into primary, secondary, iatrogenic, and traumatic. Any type of pneumothorax can then be further classified by whether it displays 'tension' pathophysiology (see Table 2).

\section{HOW IS A PNEUMOTHORAX MANAGED?}

Several different factors affect the management plan for a pneumothorax. These will include the size of the pneumothorax and the severity of the patients' symptoms, but also the ability for the patient to compensate for it, or in other words, the severity of any underlying lung disease. ${ }^{3}$

A patient presenting with symptoms and signs of a tension pneumothorax is a life-threatening emergency and must receive immediate management (please see the section below). ${ }^{3}$

According to the British Thoracic Society (BTS), primary and secondary pneumothoraces should be approached differently. The BTS guidelines also advocate a different approach dependent on the presenting size or depth of the lesion. 9 The depth of the pneumothorax is the distance between the lung edge and the inside of the chest wall on

\begin{tabular}{|l|l|}
\hline Pathology & Additional Clinical Features \\
\hline Anaphylaxis & Stridor, hypotension, lip/tongue swelling, urticaria, sense of doom. \\
\hline Pulmonary embolism & Pleuritic chest pain, tachycardia, hemoptysis. \\
\hline Pneumothorax & $\begin{array}{l}\text { Pleuritic chest pain and reduced air entry on the effected side. Some patients may be } \\
\text { asymptomatic. }\end{array}$ \\
\hline $\begin{array}{l}\text { Acute airway disease e.g. acute } \\
\text { asthma and COPD }\end{array}$ & Cough, wheeze, previously diagnosed asthma or COPD/smoking history. \\
\hline Bacterial, viral or fungal pneumonia & Fevers, rigors, malaise, cough with or without purulent sputum. Unilateral crepitations. \\
\hline Pulmonary oedema & Orthopnoea, pink frothy sputum. \\
\hline $\begin{array}{l}\text { Lung collapse due to mucous } \\
\text { plugging }\end{array}$ & $\begin{array}{l}\text { Reduced air entry with tracheal deviation towards the affected side. History of } \\
\text { productive cough, aspiration, airways disease, concurrent reduced conscious level or } \\
\text { respiratory muscle weakness. }\end{array}$ \\
\hline Hyperventilation syndrome & $\begin{array}{l}\text { Tachypnoea with normal oxygen saturations and normal respiratory examination. } \\
\text { Patient may complain of peri-oral tingling or paraesthesia in the hands and feet. }\end{array}$ \\
\hline
\end{tabular}

Table 1: Adapted from Medicine, volume 48 issue 4 and Oxford Handbook of Clinical Medicine highlighting key respiratory pathology causing acute and subacute breathlessness. ${ }^{4,5}$ 


\begin{tabular}{|c|c|}
\hline Classification & Features \\
\hline Primary & $\begin{array}{l}\text { Occurs most commonly in young, tall thin } \\
\text { males with no background of respiratory } \\
\text { disease. } \\
\text { Thought to be caused by ruptured blebs } \\
\text { (small air blisters in the lung) allowing air } \\
\text { leak into the pleural space. } \\
\text { Smoking tobacco and cannabis are } \\
\text { associated risk factors. }\end{array}$ \\
\hline Secondary & $\begin{array}{l}\text { Injury to the visceral pleura, which is } \\
\text { predisposed by respiratory disease e.g. } \\
\text { COPD (particularly bullous emphysema), } \\
\text { asthma, lung fibrosis and cancer. }\end{array}$ \\
\hline latrogenic & $\begin{array}{l}\text { Commonly caused by interventional } \\
\text { procedures such as central venous } \\
\text { cannulation (subclavian vein cannulation } \\
\text { having the highest associated risk), } \\
\text { pleural tap and even (rarely) } \\
\text { acupuncture. } \\
\text { Patients receiving mechanical ventilation } \\
\text { or non-invasive ventilation are also } \\
\text { at higher risk due to increasing intra- } \\
\text { thoracic pressures. }\end{array}$ \\
\hline Traumatic & $\begin{array}{l}\text { Occur following direct injury to the chest } \\
\text { wall. Common types of trauma include, } \\
\text { broken ribs piercing the pleura and } \\
\text { penetrating traumas to the chest. }\end{array}$ \\
\hline Tension & $\begin{array}{l}\text { Can be caused by any aetiology, but } \\
\text { most commonly due to trauma and } \\
\text { iatrogenic causes. } \\
\text { Defined as "any size of pneumothorax } \\
\text { causing mediastinal shift and } \\
\text { cardiovascular collapse" } 8\end{array}$ \\
\hline
\end{tabular}

Table 2: Adapted from Pneumothorax: an update and Oxford Handbook of Clinical Medicine..$^{5,8}$

chest X-ray, measured at the level of the lung hilum (see Figure 2)..$^{9}$ Always consult with a senior clinician before attempting to manage a pneumothorax alone. ${ }^{3,9}$

If a pneumothorax is primary, the BTS guidelines 9 advocate utilising your clinical assessment and the patient's chest $X$-ray to decide on a management plan. If the depth of the pneumothorax is less than $2 \mathrm{~cm}$, it may be safe to discharge and follow up the patient in 2-4 weeks. If the depth is more than $2 \mathrm{~cm}$ and/or the patient has dyspnoea you should attempt pleural aspiration of air before proceeding to insertion of an intercostal chest drain if this fails. ${ }^{3}$

With a secondary pneumothorax, the BTS guidelines 9 advise a low cut off, of $1 \mathrm{~cm}$ depth before intervention. If the depth is $1-2 \mathrm{~cm}$, you should attempt pleural aspiration. If a patient is breathless and/or has a depth of more than $2 \mathrm{~cm}$, it is advised that the patient should be admitted for a chest drain. If the depth is less than $1 \mathrm{~cm}$, and it is clinically appropriate, you could admit for high-flow oxygen and observation. ${ }^{3}$

Immediate, life-saving treatment of a tension pneumothorax is with the insertion of a wide-bore cannula into the second intercostal space, in the mid-clavicular line of the affected side of the chest. Locate the second intercostal

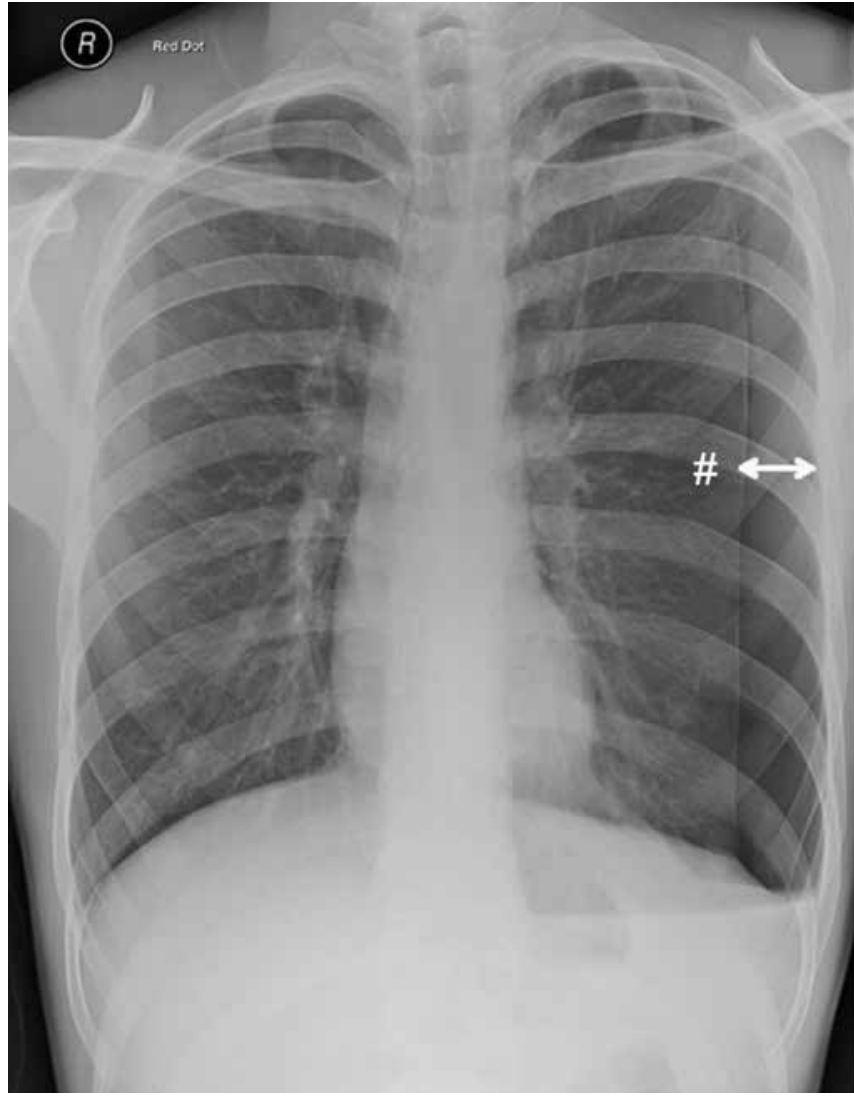

Figure 2: "\#" Measures the interpleural distance at the level of the hilum - from BTS Management of Spontaneous Pneumothorax Flowchart. ${ }^{9}$

space by palpating the angle of Lovis (which interfaces with the second ribs) and sliding your fingers into the rib-space below. The mid-clavicular line is usually in-line with the nipple. Clean the area with a chlorhexidine $2 \%$ wipe. Insert a $14 G$ (orange) or $16 \mathrm{G}$ (grey) into the space immediately above the third rib (this helps to avoid hitting the neurovascular bundle which runs below the rib in the intercostal groove). ${ }^{3}$ Remove the needle and discard in a sharps' container. In tension pneumothorax, there should be an immediate hissing sound of pressurized air leaving the thoracic cavity. This allows the high intra-pleural pressure to equilibrate with the atmosphere, facilitating normalisation of venous return to the heart ${ }^{3}$. Figure 3 highlights the anatomical positioning for pneumothorax cannula decompression.

Traditional teaching dogma dictates that intervention for tension pneumothorax should never wait for a chest X-ray. In modern times, and in the right location (emergency department resus) a chest $X$-ray can be performed without significant delay and in this circumstance, it should be performed to confirm the diagnosis and lateralise the lesion. However, in our case the patient is hypotensive, and the MET team believes that this is due to tension pneumothorax. Hypotension is a late feature of tension pneumothorax in the spontaneously breathing patient. It can occur earlier in a patient with invasive ventilation but once it occurs, the patient is peri-arrest. ${ }^{10}$ With this in mind, in the presence of hypotension it is important to intervene without delay i.e. you should proceed with pleural aspiration before a confirmatory chest $X$-ray. ${ }^{3}$ In the absence of hypotension, it may be appropriate to obtain a chest $X$-ray before proceeding with invasive interventions. 


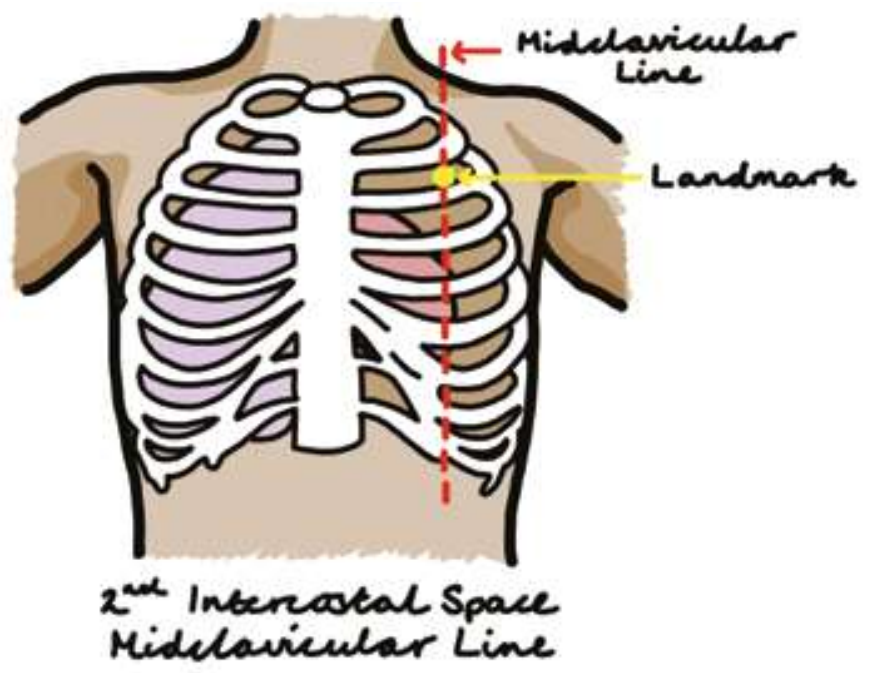

Figure 3: Highlighting the anatomical position for a cannula decompression of a pneumothorax. ${ }^{3}$

With the release of pressurised pleural air, the patient should stabilise with rising oxygen saturations and improvement in the blood pressure. You must now recognise that you have only temporised the situation; insertion of an intercostal chest drain is now the definitive intervention required to secure the patient's ongoing safety. ${ }^{3}$

\section{OUTCOME OF MR W}

In this scenario, you correctly identified that Mr. W was seriously unwell and asked for senior support quickly. You identified the clinical findings associated with a large pneumothorax and the haemodynamic instability suggestive of impending cardiovascular collapse secondary to tension pneumothorax.

The MET team arrived promptly, evaluated the patient, and agreed that a tension pneumothorax was the most likely diagnosis. The medical registrar quickly inserted a 16G cannula into the second intercostal space in the midclavicular line. Immediately, a hissing sound was heard, and within seconds the patient's distress appeared to ease and his blood pressure improved to $120 / 78$. A portable emergency chest X-ray was ordered which confirmed a large left-sided pneumothorax. The medical registrar proceeded to insertion of an intercostal chest drain and Mr W's condition continued to improve.

At the end of the shift the medical registrar took you aside and thanked you for your quick thinking and actions.

\section{KEY LEARNING OUTCOMES}

- Pneumothorax can present suddenly with dyspnea

- Pneumothorax management options range from conservative management to a variety of invasive options depending on clinical and radiological features

- A tension pneumothorax is a medical emergency and requires prompt action with needle decompression

\section{ACKNOWLEDGEMENTS}

I would like to thank Samuel Bradley, 4th Year Medical Student for producing the illustrations for this piece. His work is incredibly appreciated.

\section{DISCLAIMER}

The article is provided as a study and revision aid and is not intended to be a substitute for a formal medical education. It is important to always seek senior support in clinical practice and never work beyond your capabilities.

The Morecambe Bay Medical Journal will assume no liability to any person or entity with respect to any loss or damage related directly or indirectly to any information provided through the written articles (including any action or inaction taken or not taken because of such information).

Correspondence to: g.movio@lancaster.ac.uk

\section{REFERENCES}

1. Resuscitation Council UK. 2021. The ABCDE approach. Available at https://www.resus.org.uk/library/abcde-approach (accessed 22 September 2021)

2. Raine T, Collins G, Hall C, Hielde N. Oxford Handbook for the Foundation Program. 5th ed. Oxford: Oxford University Press; 2018

3. Chapman S, Robinson G, Stradling J, West S, Wrighton J. Oxford Handbook of Respiratory Medicine. 3rd ed. Oxford: Oxford University Press; 2014.

4. Singh S. Respiratory symptoms and signs. Medicine 2020;48:225-33. Available from: https://doi.org/10.1016/i.mpmed.2020.01.001

5. Longmore $M$, Wilkinson IB, Baldwin A, Wallin E. Oxford Handbook of Clinical Medicine. 9th ed. Oxford: Oxford University Press; 2014.

6. Kumar P, Clarke M. Clinical Medicine. 8th ed. London: Saunders Elsevier; 2012.

7. Sparke A. TeachMeAnatomy. 2020. Available from: https:// teachmeanatomy.info/thorax/organs/pleurae/ (accessed 22 September 2021)

8. Currie G, Alluri R, Christie G, Legge J. Pneumothorax: an update. Postgraduate Medical Journal. 2007;83(981):461-465. Available from: https://doi.org/10.1136/pgmj.2007.056978

9. MacDuff A, Arnold A, Harvey J. Management of spontaneous pneumothorax: British Thoracic Society pleural disease guideline 2010. Journal of the British Thoracic Society. 2010;65:18-31. Available from: https://doi.org/10.1136/thx.2010.136986

10. Leigh-Smith S, Harris T. Tension pneumothorax--time for a re-think? Emergency Medicine Journal 2004;22(1):8-16. 